\title{
A Literature Survey of Common Parasitic Zoonoses Encountered at Post-Mortem Examination in Slaughter Stocks in Tanzania: Economic and Public Health Implications
}

\author{
Erick VG Komba* \\ Department of Veterinary Medicine and Public Health, Sokoine University of Agriculture, Tanzania
}

Received: September 21, 2017; Published: October 06, 2017

*Corresponding author: Erick VG Komba, Senior lecturer, Department of Veterinary Medicine and Public Health, College of Veterinary Medicine and Biomedical Sciences, Sokoine University of Agriculture, P.O. Box 3021, Morogoro, Tanzania

\begin{abstract}
Zoonoses caused by parasites constitute a large group of infectious diseases with varying host ranges and patterns of transmission. Their distribution, prevalence and transmission patterns are affected by the influence of both human and environmental factors. The economic and public health impact of such zoonoses warrants appropriate surveillance to obtain enough information that will provide inputs in the design and implementation of control strategies. A need therefore arises to regularly re-evaluate the current status of zoonotic diseases, particularly in view of new data available as a result of surveillance activities and the application of new technologies. Consequently this paper summarizes available information in Tanzania on parasitic zoonoses encountered in slaughter stocks during post-mortem examination at slaughter facilities. The occurrence, in slaughter stocks, of fasciola spp, Echinococcus granulosus (hydatid) cysts, Taenia saginata Cysts, Taenia solium Cysts and ascaris spp. have been reported by various researchers. Information on these parasitic diseases is presented in this paper as they are the most important ones encountered in slaughter stocks in the country.
\end{abstract}

Keywords: Parasitic Zoonoses; Slaughter Stocks; Post-Mortem Examination; Traditional Sector

Abbreviations: MAFS: Ministry of Agriculture and Food security; CE: Cystic Echinococcosis; NCC: Neurocysticercosis

\section{Introduction}

In Tanzania slaughter stocks are mainly composed of cattle, pigs, goats and sheep. Most of these are supplied to the slaughter facilities by the rural based traditional livestock sector which constitutes more than $98 \%$ of the total livestock population in the country [1]. Apart from poor animal genetic makeup and poor management, the traditional livestock sector suffers high disease burden due to lack/inadequacy of veterinary services attributable to shortage of veterinary staff, poor infrastructure especially transport facilities and lack of diagnostic facilities and drugs [2-6]. As a result animals brought for slaughter into urban areas from the rural traditional sector may harbor chronic or subclinical infections some of which have zoonotic implication. Such diseases are rarely detected during ante-mortem examination and hence infected animals proceed into slaughter.

Zoonoses have been defined as diseases and infections that are naturally transmitted between vertebrate animals and humans
[7,8]. They are among the most important animal and public health problems that affect the well being of societies worldwide; and yet most of them go unrecorded and are often neglected [9]. Most zoonoses are maintained in the animal reservoir but can cross over to humans as a result of different risk factors and behavioral traits. Zoonoses caused by parasites have recently assumed an important role in public health with some of them being involved in opportunistic infections [10]. They are an important cause of human parasitic diseases worldwide and a major threat to the socio-economic development of especially developing countries [11]. The migration of humans and their domestic animals has been the pathway for disseminating parasitic zoonoses throughout recorded history and will continue to have an impact on emergency, frequency and spread of infections [12].

A slaughterhouse or abattoir refers to the premises approved and registered by the controlling authority used in the slaughter 
of animals for human consumption [13]. For a long period abattoirs have played an important role in the surveillance of various diseases of human and animal health importance [1416]. Surveillance at the abattoir is known to allow for all animals passing into the human food chain to be examined for unusual signs, lesions or specific diseases. Abattoir data are useful as they can provide a rough picture of emerging diseases [17]. As a result this paper summarizes common zoonoses encountered in slaughter stocks at abattoir during post-mortem meat inspection. It focuses on those zoonotic parasites transmitted from animals to humans. The described prevalence and distribution of various parasitic zoonoses in this paper will help responsible public health authorities in targeting of control measures and monitoring of the progress of food-safety policies.

\section{Method}

\section{Literature Search}

A literature search was conducted using the Pubmed database which comprises citations for biomedical literature from Medline, life science journals and online books. Various combinations of the following terms were used: 'Zoonotic parasites', 'Parasitic infections', 'Zoonotic, Helminths', and 'Slaughterstocks', 'cattle', 'goats', 'sheep', 'pigs', and 'abattoir', 'slaughter facility', 'slaughter house', 'postmortem inspection', and 'Tanzania'. Articles mentioned in the reference lists of the initially obtained articles were also screened to get additional articles. From the several articles detailed review of the abstracts identified 14 most relevant and representative studies of zoonotic parasitic infections encountered in slaughter stocks in the country, and these were chosen for the present paper.

\section{Results and Discussion}

\section{Fasciolosis}

Fasciolosis is a parasitic zoonosis caused by liver flukes, Fasciola gigantica and F. hepatica, belonging to the genus fasciola [18]. F. hepatica has been known to be the main causal agent as it assumes a worldwide distribution [19]. In Tanzania the disease has been reported to be among the major constraints to ruminant production in different regions [20]. Though liver fluke infestation rarely causes mortalities in cattle, much of the economic importance of the disease is due to its effect on production and economic losses owing to condemnations of the livers. Studies involving live animals have reported high prevalence rates in traditional cattle stocks in the country [20-22]. Abattoir surveys in the country have found the disease to be the commonest and a leading cause of liver condemnations in slaughter cattle [2,3,5,20,23,24]. A study by Keyyu et al. [21] reported up to $100 \%$ liver condemnation rates in some slaughter slabs in rural areas in Iringa region due to liver flukes in cattle.

Reports also exist on detection of the disease in small ruminants during post-mortem inspection [3,5], prevalence rates ranging from $3.1 \%$ to $17.1 \%$ (Sheep) and $3.1 \%$ to $18.5 \%$ (Goats). However, small ruminants suffer from an acute form of the disease which is normally associated with high mortalities $[25,26]$. The proportion contributions of fasciolosis to total liver condemnations in the reported studies may not be a true reflection of infections in slaughter stocks since there are many light infections in which affected parts are trimmed and the remaining portion passed for human consumption and these are not recorded $[2,5,6]$. Apart from its importance in veterinary and economic terms, fasciolosis has been shown to be a reemerging and widespread zoonosis affecting a number of human populations throughout the world $[27,28]$. According to Mas Coma et al. [28] emergence/re-emergence of the disease in many countries is an attribute of many phenomena related to environmental changes and manmade modifications. Together with other trematodiases the disease is included in a list of important helminthiases with a great impact on human development.

\section{Cystic Echinococcosis /Hydatid Disease}

Cystic Echinococcosis (CE) is a zoonotic disease caused by larval stage of the tape worm, Echinococcus granulosus, whose adult forms are seen in carnivores [29,30]. Ungulates and humans act as intermediate hosts for the parasite with human infections being caused by ingestion of the tapeworm eggs while playing with infected dogs containing eggs in the fur or through consumption of garden vegetables or water contaminated by dog feces [31]. The organism assumes a cosmopolitan distribution but is endemic in the Mediterranean, Africa, Middle East, South America, Aus $\neg$ tralia, Russia, and China where livestock, mainly sheep and cattle, are raised with dogs who harbor the adult phase of the tapeworm [2935]. Echinococcus granulosus causes serious lung and liver disease [36-40] and less frequently affects the kidney, peritoneum, spleen [31]. Maintanance and spread of the disease in endemic areas are known to be influenced by the diversity of livestock production systems, poor and unsupervised slaughter-houses, illegal and family slaughtering, low public awareness of the disease, and a large stray dog population [35].

Apart from exerting health effects to both humans and animals, hydatid cysts have important economic consequences [41]. On the human side economic losses arise through diagnostic cost, treatment cost, hospitalization, convalescence, life impairment and fatal outcomes. In animals economic losses are observed in decreased carcass weight, milk production and fertility rates, and from increased rate of condemnation of affected organs. In intermediate hosts (ungulates), cysts of E. granulosus are usually detected bat post-mortem abattoir examination of the viscera [42], providing important epidemiological data, which can be used to define likely Echinococcal infection pressure [43-45]. Abattoir based studies in the country (Tanzania) have revealed that the disease is prevalent among slaughter stocks particularly cattle $[2,4-6,46,47]$ as well as sheep and goats [4-6,48]. A study by Braae et al. [48] also detected the parasites in $6.6 \%$ of the slaughter pigs they examined $(n=243)$. Some other studies reported occurrence of the disease in humans more so in pastoral communities $[49,50]$. Studies elsewhere in pastoralist communities in other African countries [51-60] and other continents $[61,62]$ also showed evidence of existence of the disease in humans and domestic animals particularly cattle, sheep and goats. Poor sanitation and hygiene, and unrestricted disposal 
of animal viscera post-slaughter may be responsible for the high prevalence Echinococcosis.

\section{Taenia saginata Cysticercosis}

Taenia saginata is a two host parasite whose larval stage, known as Cysticercus bovis, is found in cattle, and the adult tapeworm, Taenia saginata, is found in intestines of man $[63,64]$. The cycle is completed when eggs in gravid proglottids shed from the human tapeworm are ingested by cattle, and viable cysts in undercooked beef are consumed by man $[63,65]$. The public health and economic consequences of infection of cattle with metacestodes of this worldwide occurring human tapeworm are considerable [66]. In humans infected individuals may remain asymptomatic for years, and the only symptom may be the spontaneous passage of proglottids. However, non-specific symptoms, such as vague abdominal pain, vomiting, nausea, diarrhea and weight loss can be present [67]. Although the tapeworm seems to be a benign parasitic disease, it can lead to serious surgical Gastrointestinal System (GIS) complications that are seldom reported in the medical literature [67-69]. In Tanzania a number of works have reported occurrence of the parasite in slaughter cattle $[2,4-6,47]$. Though the prevalence rates were fairly small (less than $2 \%$ ) the implication thereof is significant. Low prevalence rates of the parasite in slaughter cattle have also been reported in other countries [70].

\section{Taenia solium Cysticercosis}

Porcine cysticercosis is a parasitic zoonosis caused by the larval stage of a tapeworm Taenia solium [71]. The disease is endemic in most developing countries of Latin America, Asia and sub-Saharan Africa where pork is consumed causing serious public health and agricultural consequences [72-76]. While pigs are the intermediate hosts, man is the only natural definitive host. Pigs usually get infected by eating infected human feces or by consuming feed or water contaminated with human feces. Humans can also become accidental intermediate hosts upon ingestion of T. solium eggs $[77,78]$. In both humans and pigs, the larval stage of T. solium can establish in the muscles and/or in the brain, the latter resulting in Neurocysticercosis (NCC), which is the most common cause of human acquired epilepsy in many developing countries and accounts for over 20 million cases and 50000 deaths each year $[73,79]$. NCC is a neglected disease, and its prevalence is largely underestimated [80]. Human NCC may lead to acute seizures, epilepsy and other neurological manifestations [81]. Ingestion of larvae (Cysticerci) present in raw or under-cooked pork may result in human tapeworm infection.

In Tanzania several abattoir surveys have been conducted to establish the existence of porcine Cysticercosis in slaughter pigs [6,82-85]. Prevalence rates as high as $24.4 \%$ [83] have been reported in slaughter pigs. The detection of the parasites in live animals has also been attempted [83,85-88] revealing high prevalence of the disease in rural communities where traditional pig husbandry is practiced. Studies in slaughter and live animals in other countries in the East and central African region have also found the disease to be prevalent in the traditional pig husbandry [89-96]. Several studies in endemic areas have associated the disease with free ranging pig husbandry, poor sanitary practices and lack of veterinary control, all related to poverty $[77,86,97,98]$.

\section{Ascariosis}

Ascaris suum is a nematode found in pigs causing a disease known as ascariosis [99]. Human infections with Ascaris suum such as cases with larva migrans and eosinophilic pneumonia have been reported [100-105]. In some molecular studies carried out in some regions on human intestines, Ascaris suum infections were determined to be prevalent [99]. Infections in humans and other mammalians result from the ingestion of food and water contaminated by A. suum eggs. Several studies have investigated occurrence of ascariosis in slaughter pigs in Tanzania $[6,84,86]$, reporting different rates. A low rate of $4.03 \%$ was reported by Mellau et al. [6] in a record based study in northern part of the country whereas Ngowi et al. [86] reported the highest rate of $44.3 \%$ in a different location of the same part of the country. A lower rate of ascariosis (4.1\%) has been reported in Turkey [99] whereas rates as higher as $54.5 \%$ and $36.7 \%$ have been reported in Botswana [106] and in China [107]. According to Olson and Guselle [103], $50 \%$ to $70 \%$ of pigs are estimated to be infected by A. suum in the world. Differences in reported prevalence may be attributable to limitations of abattoir records (record based studies), pig management systems, diagnosis methods used [6] and differences in levels of anthelmintic use among pig producers [84]. The observed prevalence of the condition in slaughter pigs in the country is of economic and public health importance due to zoonotic nature of the disease [108]. Some further work is however needed to establish factors responsible for transmission and maintenance of ascariosis and to evaluate the implication of the parasite in economic and public health terms.

\section{Conclusion}

Parasitic zoonoses are prevalent among livestock destined for human consumption in Tanzania. Reported prevalence rates of these conditions have enormous economic and public health implications. As revealed by large quantities of condemned organs and/or carcasses, post mortem meat inspection is playing an outstanding role in safeguarding consumers' health in Tanzania. Sadly, such large quantities of condemned organs and/or carcasses have a huge negative impact on the economy of farmers and the country at large. Although the abattoir survey reports collated and availed in this review are not juxtaposing true estimates of the prevalence of parasitic zoonoses in Tanzania, they still provide good overview of the trend and status of these zoonoses in the country; and can therefore guide in planning future co-ordinated researches and control programs.

\section{References}

1. Ministry of Agriculture Food Security, MAFS, Basic Data-Agriculture Sector (2002) Statistics Unit, MAFS, Tanzania, p. 72.

2. Kambarage DM, Kimera SI, Kazwala RR, Mafwere BM (1995) Disease conditions responsible for condemnation of carcasses and organs in short-horn Zebu cattle slaughtered in Tanzania. Preventive Veterinary Medicine 22(4): 249-255. 
3. Nonga HE, Mwabonimana MF, Ngowi HA, Mellau LSB, Karimuribo ED (2009) A retrospective survey of liver fasciolosis and stilesiosis in livestock based on abattoir data in Arusha, Tanzania. Tropical Animal Health and Production 41(7): 1377-1380.

4. Mellau LSB, Nonga HE, Karimuribo ED (2010) A slaughterhouse survey of lung lesions in slaughtered stocks at Arusha, Tanzania. Preventive Veterinary Medicine 97(2): 77-82.

5. Mellau LSB, Nonga HE, Karimuribo ED (2010) A slaughterhouse survey of liver lesions in slaughtered cattle, sheep and goats at Arusha, Tanzania. Research Journal of Veterinary Sciences 3(3): 179-188.

6. Mellau BL, Nonga HE, Karimuribo ED (2011) Slaughter stock abattoir survey of carcasses and organ/offal condemnations in Arusha region, northern Tanzania. Tropical Animal Health and Production 43(4): 857864.

7. World Health Organization (2010) WHO Zoonoses. Geneva: World Health Organization. World Health Organization website.

8. Havelaar AH, van Rosse F, Bucura C, Toetenel MA, Haagsma JA, et al. (2010) Prioritizing Emerging Zoonoses in The Netherlands. PLoS ONE 5(11): 13965.

9. Zinsstag J, Schelling E, Roth F, Bonfoh B, de Savigny D, et al. (2007) Human Benefits of Animal Interventions for Zoonosis Control. Emerging Infectious Diseases 13(4): 521-531.

10. Altintas N (2008) Parasitic zoonoses in Turkey. Veterinaria Italiana 44(4): 633-646.

11. Otranto D, Eberhard ML (2011) Zoonotic helminths affecting the human eye. Parasites and Vectors 4: 41.

12. Macpherson CN (2005) Human behaviour and the epidemiology of parasitic zoonoses. International Journal of Parasitology 35(11): 13191331.

13. Alonge DO (1991) Textbook of Meat Hygiene in the Tropics. Ibadan, Farmcoe Press, Nigeria.

14. Vilas VJDR, Bohning D, Kuhnert R (2008) A comparison of the active surveillance of scrapie in the European Union. Veterinary Research $39(2): 37-52$

15. Hadorn DC, Stark KDC (2008) Evaluation and optimization of surveillance systems for rare and emerging infectious diseases. Veterinary Research 39(6): 57-69.

16. Karama M, Johnson RP, Holtslander R, McEwen SA, Gyles CL (2008) Prevalence and characterization of verotoxin-producing Escherichia coli (VTEC) in cattle from an Ontario abattoir. Canadian Journal of Veterinary Research 72(4): 297-302.

17. Gillian D Alton, David L Pearl, Ken G Bateman, W Bruce McNab, Olaf Berke (2010) Factors associated with whole carcass condemnation rates in provincially-inspected abattoirs in Ontario 2001-2007: implications for food animal syndromic surveillance. Veterinary Research 6: 42.

18. Rivera Jacinto M, Rodríguez Ulloa C, Rojas Huamán Y, Valdivia Meléndez Y, Saucedo Duran T (2010) Knowledge, attitudes and practices about fascioliasis among mothers from an Andean rural area of north Peru. Rev Peru Med Exp Salud Publica. 27(1): 59-62.

19. Mas Coma S, Valero MA, Bargues MD (2009) Fasciola, Lymnaeids and human fascioliasis, with a global overview on disease transmission, epidemiology, evolutionary genetics, molecular epidemiology and control. Advances in Parasitology 69: 141-146.

20. Keyyu JD, Kassuku, AA, Msalilwa LP, Monrad J, Kyvsgaard NC (2006) Cross-sectional prevalence of helminth infection in cattle on traditional, small-scale and large-scale dairy farms in Iringa district, Tanzania. Vet Res Comm 30(1): 45-55.

21. Keyyu JD, Monrad J, Kyvsgaard NC, Kassuku AA (2005) Epidemiology of Fasciola gigantica and Amphistomes in cattle on traditional, small-scale dairy and large-scale dairy farms in the Southern Highlands of Tanzania. Tropical Animal Health and Production 37(4): 303-314.
22. Swai ES, Mtui PF, Mbise AN, Kaaya E, Sanka P, et al. (2006) Prevalence of gastro intestinal parasite infections in Maasai cattle in Ngorongoro District, Tanzania. Livestock Research for Rural Development 18(8): 107.

23. Hyera JKM (1984) Prevalence, seasonal variation and economic significance of fasciolasis in cattle as observed in Iringa abattoir between 1976 and 1980. Bull Anim Health Prod Afr 32: 356- 359.

24. Mwabonimana MF, Kassuku AA, Ngowi HA, Mellau LSB, Nonga HE, et al. (2009) Prevalence and economic significance of bovine fasciolosis in slaughtered cattle at Arusha abattoir, Tanzania. Tanzania Veterinary Journal 26(2): 68-74.

25. Kusiluka LJM, Kambarage DM (1996) Diseases of Small Ruminants in Subsaharan Africa: A Hand Book on Common Diseases of Sheep and Goats in Sub-Saharan Africa. VETAID 116pp.

26. Nsengwa, GRM, Dulle CK, Keyyu JD, Kassuku AA (2001) An outbreak of acute fasciolosis confined to sheep in a farm in Iringa. Case report. In Proceedings of the $17^{\text {th }}$ Tanzania Veterinary Association (TVA) Scientific Conference, AICC, Arusha, Tanzania p. 18.

27. Esteban JG, Gonzalez C, Curtale F, Muñoz-antoli C, Valero MA, et al. (2003) Hyperendemic fascioliasis associated with schistosomaisis in villages in the Nile delta of Egypt. Am J Trop Med Hyg. 69(4): 429-437.

28. Mas-Coma S, Bargues MD, Valero MA (2005) Fascioliasis and other plantborne trematode zoonoses. Ineternational Journal of Parasitology 35(11-12): 1255-1278.

29. Eckert J, Deplazes P (2004) Biological, epidemiological, and clinical aspects of echinococcosis, a zoonosis of increasing concern. Clin. Microbiol. Rev. 17(1): 107-135.

30. Budke CM, Deplazes P, Torgerson P (2006) Global socioeconomic impact of cystic echinococcosis. Emerging Infectious Diseases 12(2): 296-303.

31. Scarlata F, Giordano S, Saporito L, Marasa L, Li Pani G, et al. (2011) Cystic hydatidosis: a rare case of spine localization. Infez Med. 19(1): 39-41.

32. Radfar MH, Iranyar N (2004) Biochemical profiles of hydatid cyst fluids of E. granulosus of human and animal origin in Iran. Veterinarski Arhir. 74(6): 435-442.

33. Foster EN, Hertz G (2010) Echinococcus of the Liver Treated with Laparoscopic Hepatectomy. Perm J. 14(2): 45-46.

34. Dakkak A (2010) Echinococcosis/hydatidosis: A severe threat in Mediterranean countries. Veterinary Parasitology 174(1-2): 2-11

35. Sotiraki S, Chaligiannis I (2010) Cystic echinococcosis in Greece. Past and present. Parasite 17(3): 205-210.

36. Morris DL, Clarkson MJ, Stallbaumer MF, Pritchard J, Jones RS, et al. (985) Albendazole treatment of pulmonary hydatid cysts in naturally infected sheep: a study with relevance to the treatment of hydatid cysts in man. Thorax 40(6): 453-458.

37. Dueger EL, Moro PL, Gilman RH (1999) Oxfendazole treatment of sheep with naturally acquired hydatid disease. Antimicrob Agents Chemother 43(9): 2263-2267.

38. Chin J (2000) Control of communicable disease manual. 17th ed. Public Health Association, Washington, USA, 624pp.

39. Sayek I, Tirnaksiz MB, Dogan R: (2004) Cystic hydatid disease: current trends in diagnosis and management. Surg Today, 34(12): 987-996

40. Brunetti E, Garcia HH, Junghanss T (2011) Cystic Echinococcosis: Chronic, Complex, and Still Neglected. PLoS Negl Trop Dis 5(7): e1146.

41. Torgerson PR (2003) Economic effects of echinococcosis. Acta Tropica 85(2): 113-118.

42. Yang YR, McManus DP, Huang Y, Heath DD (2009) Echinococcus granulosus Infection and Options for Control of Cystic Echinococcosis in Tibetan Communities of Western Sichuan Province, China. PLoS Neglected Tropical Diseases 3(4): e426. 
43. Ming R, Tolley HD, Andersen FL, Chai J, Chang Q (1992) Frequency distribution of Echinococcus granulosus in dog populations in the Xinjiang Uygur Autonomous Region, China. Veterinary Parasitology 43: 233-241.

44. Cabrera PA, Parietti S, Haran G, Benavidez U, Lloyd S, et al. (1996) Rates of reinfection with Echinococcus granulosus, Taenia hydatigena, Taenia ovis and other cestodes in a rural dog population in Uruguay. International Journal of Parasitology 26(1): 79-83.

45. Torgerson PR, Williams DH, Abo-Shehada MN (1998) Modelling the prevalence of Echinococcus and Taenia species in small ruminants of different ages in northern Jordan. Veterinary Parasitology 79(1): 35-51.

46. Nonga HE, Karimuribo ED (2009) A retrospective survey of hydatidosis in livestock in Arusha, Tanzania, based on abattoir data during 20052007. Tropical Animal Health and Production 41(7): 1253-1257.

47. Swai ES, Schoonman L, (2012) A survey of zoonotic diseases in trade cattle slaughtered at Tanga city abattoir: a cause of public health concern. Asian Pacific Journal of Tropical Biomedicine 2(1): 55-60.

48. Braae UC, Kabululu M, Nørmark ME, Nejsum P, Ngowi HA, et al. (2015). Taenia hydatigena cysticercosis in slaughtered pigs, goats, and sheep in Tanzania. Tropical Animal Health and Production 47(8): 1523-1530.

49. Macpherson CN L, Spoerry A, Zehyle E, Romig T, Gorfe M (1989) Pastoralists and hydatid disease: an ultrasound scanning prevalence survey in East Africa. Trans. R. Soc. Trop. Med. Hyg. 83(2): 243-247.

50. Ernest E, Nonga .E, Kynsieri N, Cleaveland S (2010) A retrospective survey of human hydatidosis based on hospital records during the period 1990-2003 in Ngorongoro, Tanzania. Zoonoses and Public Health 57(7-8): 124-129.

51. Magambo JK, Wachira TM, Zeyhle E, Mwaura J: (1996) Prevalence of human hydatid disease in southern Sudan. Afr. J. Health Sci., 3(4): 154156.

52. Magambo JK, Zeyhle E, Wachira T (1998) Hydatid disease in Toposaland southern Sudan. Afr. J. Health Sci 5(3-4): 129-132.

53. Coulibaly ND, Yameogo K (2000) Prevalence and control of zoonotic disease: collaboration between public health workers and veterinarians in Burkina Faso. Acta Tropica 76(1): 53-57.

54. Magaji AA, Bello OS, Oboegbulem SI, Garba HS,, Daneji AI, et al. (2004) Research impediments in echinococcosis/hydatidosis in a resource poor country Nigeria. Int. Arch. Hydatid, 35: 76.

55. Elmahdi, IE, Ali QM, Magzoub MM, Abrahim AM, Saad MB, et al. (2004) Cystic echinococcosis of livestock and humans in central Sudan. Ann. Trop. Med. Parasitol 98(5): 473-479.

56. Macpherson CNL, Kachani M, Lyagoubi M, Berada M, Bouslikhane M, et al (2004) Cystic echinococcosis in the Berber of the Mid Atlas Mountains, Morocco: new insights into the natural history of cystic hydatid disease in humans. Ann. Trop. Med. Parasitol. 98: 481-490.

57. Azlaf R, Dakkak A (2006) Epidemiological study of the cystic echinococcosis in Morocco. Veterinary Parasitology 137: 83-93.

58. Kebede N, Mitiku A, Tilahun G (2009) Hydatidosis of slaughtered animals in Bahir Dar Abattoir, Northwestern Ethiopia. Tropical Animal Health and Production 41(1): 43-50.

59. Tolosa T, Tigre W, Teka G, Dorny P (2009) Prevalence of bovine cysticercosis and hydatidosis in Jimma municipal abattoir, South West Ethiopia. Onderstepoort J Vet Res 76(3): 323-326.

60. Getaw A, Beyene D, Ayana D, Megersa B, Abunna F (2010) Hydatidosis: prevalence and its economic importance in ruminants slaughtered at Adama municipal abattoir, Central Oromia, Ethiopia. Acta Tropica 113(3): 221-225

61. Ito A, Wandra T, Sato MO, Mamuti W, Xiao N, et al. (2006) Towards the international collaboration for detection, surveillance and control of taeniasis/ cysticercosis and echinococcosis in Asia and the Pacific. Southeast Asian J Trop Med Public Health 37(3): 82-90.

62. Wang Z, Wang X, Liu X (2008) Echinococcosis in China, a review of the epidemiology of Echinococcus spp. Ecohealth 5(2): 115-126.

63. Bordon LM (1992) Intestinal obstruction due to Taenia saginata infection: a case report. J Trop Med Hyg 95(5): 352-353.

64. Lees W, Nightingale J, Brown D, Scandrett, B (2002) Outbreak of Cysticercus bovis (Taenia saginata) in feedlot cattle in Alberta. Canadian Veterinary Journal 43(3): 227-228.

65. Ogunremi O, MacDonald G, Geerts S, Brandt J (2004) Diagnosis of Taenia saginata cysticercosis by immunohistochemical test on formalin-fixed and paraffin-embedded lesions. J Vet Diagn Invest 16(5): 438-441.

66. Pawlowski ZK, Murrell D (2001) Taeniasis and Cysticercosis. In Food Bore Disease Handbook. Second Edition. Edited by Hui YH, Sattar SA, Murrell KD, Nip WK, Stanfield PS, New York, Marcel Dekker, USA, pp. 217-227.

67. Karanikas ID, Sakellaridis TE, Alexiou CP, Siaperas PA, Fotopoulos AC, et al. (2007) Taenia saginata: a rare cause of bowel obstruction. Trans $R$ Soc Trop Med Hyg. 101(5): 527-528.

68. Chirdan LB, Yusufu LM, Ameh EA, Shehu SM (2001) Meckel's diverticulitis due to Taenia saginata: case report. East Afr Med J. 78(2): 107-108.

69. Jongwutiwes S, Putaporntip C, Chantachum N, Sampatanukul P (2004) Jejunal perforation caused by morphologically abnormal Taenia saginata saginata infection. J Infect. 49(4): 324-328.

70. Tolosa T, Tigre W, Teka G, Dorny P (2009) Prevalence of bovine cysticercosis and hydatidosis in Jimma municipal abattoir, South West Ethiopia. Onderstepoort J Vet Res. 76(3): 323-326.

71. Ganaba R, Praet N, Carabin H, Millogo A, Tarnagda Z, et al. (2011) Factors Associated with the Prevalence of Circulating Antigens to Porcine Cysticercosis in Three Villages of Burkina Faso. PLoS Negl Trop Dis 5(1): e927.

72. Sarti E, Schantz PM, Plancarte A, Wilson M, Guiterez IO, et al. (1992) Prevalence and risk factors for Taenia solium taeniasis and cysticercosis in humans and pigs in a village in Morelos, Mexico. Am. J. Trop. Med. Hyg 46(4): 677-685.

73. Román G, Sotelo J, Del Brutto 0, Flisser A, Dumas M, et al. (2000) A proposal to declare neurocysticercosis an international reportable disease. Bull World Health Organ 78(3): 399-406.

74. Zoli AP., Shey-Njila O, Assana E, Nguekam, Dorny P, et al. (2003) Regional status, epidemiology and impact of Taenia solium cysticercosis in Western and Central Africa. Acta Tropica 87(1): 35-42.

75. Carabin H, Krecek RC, Cowan LD, Michael L, Foyaca-Sibat H, et al. (2006) Estimation of the cost of Taenia solium cysticercosis in Eastern Cape Province, South Africa. Trop Med Int Health. 11(6): 906-916.

76. Praet N, Speybroeck N, Manzanedo R, Berkvens D, Nsame Nforninwe D, et al. (2009) The disease burden of Taenia solium cysticercosis. PLoS Neglected Tropial Diseases 3(3): e406.

77. Garcia HH, Araoz R, Gilman RH, Valdez J, Gonzalez AE, et al. (1998) Increased prevalence of cysticercosis and taeniasis among professional fried pork vendors and the general population of a village in the peruvian highlands. Am J Trop Med Hyg 59(6): 902-905.

78. Gonzalez AE, Garcia HH, Gilman RH, Tsang VCW (2003) Cysticercosis Working Group in Peru: Control of Taenia solium. Acta Tropica 87: 103109.

79. García HH, Gonzalez AE, Evans CAW, Gilman RH (2003) Taenia solium cysticercosis. Lancet 336(9383): 547-556.

80. Geerts S, Zoli A, Willingham L, Brandt J, Dorny P, et al. (2002) Taenia solium cysticercosis in Africa: an under-recognised problem. In: Cestode Zoonoses: Echinococcosis and Cysticercosis an Emergent and Global 
Problem. Edited by Craig PH, Pawlowski Z. Amsterdam, The Netherlands: IOS Press; $13-23$.

81. Garcia HH, Del Brutto OH (2005) Neurocysticercosis: updated concepts about an old disease. Lancet Neurol 4(10): 653-661.

82. Boa ME, Bøgh HO, Kassuku AA, Nansen P (1995) The prevalence of Taenia solium metacestodes in pigs in northern Tanzania. Journal of Helminthology 69(2): 113-117.

83. Boa ME, Mahundi EA, Kassuku AA, Willingham III AL, Kyvsgaard NC (2006) Epidemiological survey of swinecysticercosis using antemortem and post-mortem examination tests in the southern highlands of Tanzania. Veterinary Parasitology 139(1-3): 249-255.

84. Mkupasi EM, Ngowi HA, Nonga HE (2011) Slaughter Slab Survey for Extra-Intestinal Porcine Helminth Infections in Dar es salaam City, Tanzania. Tropical Animal Health and Production 43(2): 417-423.

85. Kavishe M D B, Mkupasi E M, Komba E V G and Ngowi H A (2017) Prevalence and risk factors associated with porcine cysticercosis transmission in Babati district, Tanzania. Livestock Research for Rural Development.

86. Ngowi HA, Kassuku AA, Maeda GE, Boa ME, Carabin H, et al. (2004) Risk factors for the prevalence of porcine cysticercosis in Mbulu District, Tanzania. Vet Parasitol, 120(4): 275-283.

87. Komba EVG, Kimbi EC, Ngowi HA, Kimera SI, Mlangwa JE, et al. (2013) Prevalence of porcine cysticercosis and associated risk factors in smallholder pig production systems in Mbeya region, southern highlands of Tanzania. Veterinary parasitology 198(3-4): 284- 291.

88. Kabululu ML, Ngowi HA, Kimera SI, Lekule FP, Kimbi EC, et al. (2015) Risk factors for prevalence of pig parasitoses in Mbeya Region, Tanzania. Vet Parasitol. 212(3-4): 460-464.

89. Viljoen NF (1937) Cysticercosis in swine and bovines, with special reference to South African conditions. Onderstepoort J. Vet. Sci. Anim. Ind. 9: 337-570.

90. Heinz HJ, MacNab GM (1965) Cysticercosis in the Bantu of Southern Africa. S Afr J Med Sci. 30: 19-31.

91. Anyanzo T (1999) Prevalence of Cysticercosis cellulosae in three subcounties of Moyo County, Moyo District, Uganda. Bachelor of Veterinary Medicine Special project report. Makerere University, Faculty of Medicine.

92. Afonso SMS, Neves L, Afonso CMCS, Nota A, Vilhena M, et al. (2001) Cysticercosis cellulosae in Tete Province, Mozambique. In Proceedings of the Workshop on Human Helminth Infections 'Future Research Foci: Lusaka, Zambia, pp. 32.

93. Kisakye JJM, Masaba SC (2002) Cysticercus cellulosae in pigs slaughtered in and around Kampala City. Uganda. Journal of Agricultural Sciences $7(2): 23-24$.

94. Phiri IK, Gabriel S, Dorny P, Willingham AL, Vercruysse J (2001) Cysticercosis in Zambia. In Proceedings of the $18^{\text {th }}$ International Conference of the World Association for the Advancement of Veterinary Parasitology, Stresa, Italy, p. 26-30.
95. Phiri IK, Dorny P, Gabriel S, Willingham AL, Speybroeck N, et al. (2002) The prevalence of porcine cysticercosis in Eastern and Southern Provinces of Zambia. Veterinary Parasitology 108: 31-39.

96. Matenga E, Mukaratirwa S, Willingham AL (2002) Prevalence of porcine cysticercosis and hydatidosis in slaughtered animals in southwestern Zimbabwe: a retrospective study. In Proceedings of the 11th Annual Meeting of ENRECA Livestock Helminths Research Project in Eastern and Southern Africa, Lusaka, Zambia, p. 6-9.

97. Phiri IK, Ngowi H, Afonso S, Matenga E, Boa M, et al. (2003) The emergence of Taenia solium cysticercosis in Eastern and Southern Africa as a serious agricultural problem and public health risk. Acta Tropica 87(1): 13-23.

98. Pondja A, Neves L, Mlangwa J, Afonso S, Fafetine J, et al. (2010) Prevalence and Risk Factors of Porcine Cysticercosis in Ango'nia District, Mozambique. PLoS Neglected Tropical Diseases 4(2): e594.

99. Uysal HK, Boral Ö, Metiner K, Ilgaz A (2009) Investigation of Intestinal Parasites in Pig Feces That Are also Human Pathogens. Türkiye Parazitoloji Dergisi 33(3): 218-221.

100. Anderson TJ (1995) Ascaris infections in humans from North America: molecular evidence for cross-infection. Parasitology 110(2): 215-219.

101. Maruyama H, Nawa Y, Noda S, Mimori T (1997) An outbreak of ascariasis with marked eosinophilia in the southern part of Kyushu District, Japan, caused by infection with swine ascaris. Southeast Asian J. Trop. Med. Public Health 28(1): 194-196.

102. Inatomi $\mathrm{Y}$, Murakami $\mathrm{T}$, Tokunaga $\mathrm{M}$, Ishiwata $\mathrm{K}$, Nawa $\mathrm{Y}$, et al. (1999) Encephalopathy caused by visceral larva migrans due to Ascaris suum. J Neurol Sci 164(2): 195-199.

103. Olson ME, Guselle N (2000) Are pig parasites a human health risk? Adv Pork Production 11: 153-162.

104. Sakakibara A, Baba K, Niwa S, Yag T, Wakayama H, et al. (2002) Visceral larva migrans due to Ascaris suum which presented with eosinophilic pneumonia and multiple intra-hepatic lesions with severe eosinophil infiltration-outbreak in a Japanese area other than Kyushu. Intern Med 41(7): 574-579.

105. Yoshida S, Matsui M, Wang HY, Oeda T, Sasaki T, et al. (2004) A case of myeloradiculitis as a complication of visceral larva migrans due to Ascaris suum. Rinsho Shinkeigaku 44(3): 198-202.

106. Nsoso SJ, Mosala KP, Ndebele RT, Ramabu SS (2000) The prevalence of internal and external parasites in pigs of different ages and sexes in Southeast District, Bostwana. Onderstepoort Journal of Veterinary Research 67(3): 217-220.

107. Boes J, Willingham 3rd AL, Fuhui S, Xuguang H, Eriksen L, et al. (2000) Prevalence and distribution of pig helminths in the Dongting Lake Region (Human Province) of the people's republic of China. Journal of Helminthology 74(1): 45-52.

108. Nejsum P, Parker ED Jr, Frydenberg J, Roepstorff A, Boes J, et al. (2005) Ascaris is a zoonosis in Denmark. Journal of Clinical Microbiology 43(3): 1142-1148.

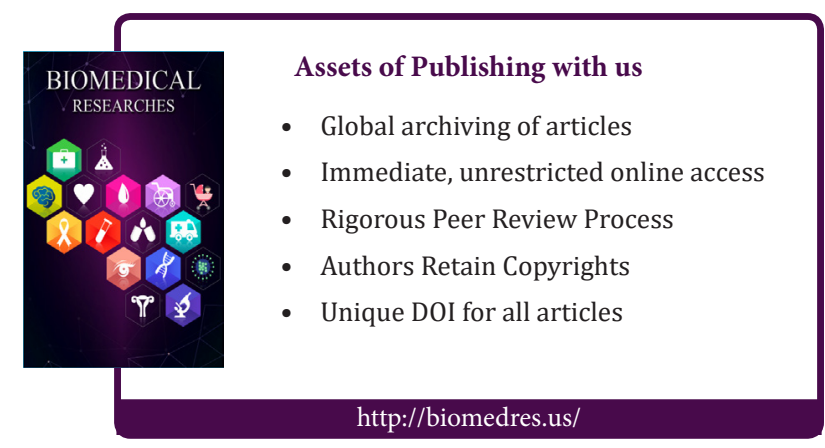

